\title{
Integrative computational analysis of transcriptional and epigenetic alterations implicates $D T X 1$ as a putative tumor suppressor gene in HNSCC
}

\author{
Daria A. Gaykalova ${ }^{1}$, Veronika Zizkova ${ }^{1,2}$, Theresa Guo ${ }^{1}$, Ilse Tiscareno ${ }^{1}$, Yingying \\ Wei $^{3,10}$, Rajita Vatapalli' ${ }^{1,4}$, Patrick T. Hennessey ${ }^{1,5}$, Julie Ahn ${ }^{1}$, Ludmila Danilova ${ }^{3,11}$, \\ Zubair Khan ${ }^{1}$, Justin A. Bishop ${ }^{1,6}$, J. Silvio Gutkind ${ }^{7}$, Wayne M. Koch ${ }^{1}$, William H. \\ Westra $^{1,6}$, Elana J. Fertig ${ }^{3}$, Michael F. Ochs ${ }^{3,8}$, Joseph A. Califano ${ }^{1,9}$ \\ ${ }^{1}$ Department of Otolaryngology-Head and Neck Surgery, Johns Hopkins Medical Institutions, Baltimore, Maryland, USA \\ ${ }^{2}$ Institute of Molecular and Translational Medicine, Faculty of Medicine and Dentistry, Palacky University, Olomouc, Czech \\ Republic \\ ${ }^{3}$ Division of Oncology Biostatistics, Department of Oncology, Johns Hopkins Medical Institutions, Baltimore, Maryland, USA \\ ${ }^{4}$ Department of Urology, Northwestern University, Chicago, Illinois, USA \\ ${ }^{5}$ Department of Otolaryngology, Mid-Michigan Ear Nose and Throat, East Lansing, Michigan, USA \\ ${ }^{6}$ Department of Pathology, Johns Hopkins Medical Institutions, Baltimore, Maryland, USA \\ ${ }^{7}$ Department of Pharmacology, UC San Diego Moores Cancer Center, La Jolla, California, USA \\ ${ }^{8}$ Department of Mathematics and Statistics, The College of New Jersey, Ewing, New Jersey, USA \\ ${ }^{9}$ Department of Surgery, UC San Diego, Moores Cancer Center, La Jolla, California, USA \\ ${ }^{10}$ Department of Statistics, The Chinese University of Hong Kong, NT, Shatin, Hong Kong \\ ${ }^{11}$ Laboratory of Systems Biology and Computational Genetics, Vavilov Institute of General Genetics, Russian Academy of \\ Sciences, Moscow, Russia
}

Correspondence to: Joseph A. Califano, email: jcalifano@ucsd.edu Daria A. Gaykalova, email: dgaykal1@jhmi.edu

Keywords: HNSCC, DTX1, expression, methylation, integration

Received: September 07, 2016

Accepted: January 16, 2017

Published: January 27, 2017

\section{ABSTRACT}

Over a half million new cases of Head and Neck Squamous Cell Carcinoma (HNSCC) are diagnosed annually worldwide, however, 5 year overall survival is only $\mathbf{5 0} \%$ for HNSCC patients. Recently, high throughput technologies have accelerated the genome-wide characterization of HNSCC. However, comprehensive pipelines with statistical algorithms that account for HNSCC biology and perform independent confirmatory and functional validation of candidates are needed to identify the most biologically relevant genes. We applied outlier statistics to high throughput gene expression data, and identified 76 top-scoring candidates with significant differential expression in tumors compared to normal tissues. We identified 15 epigenetically regulated candidates by focusing on a subset of the genes with a negative correlation between gene expression and promoter methylation. Differential expression and methylation of 3 selected candidates (BANK1, BIN2, and DTX1) were confirmed in an independent HNSCC cohorts from Johns Hopkins and TCGA (The Cancer Genome Atlas). We further performed functional evaluation of NOTCH regulator, DTX1, which was downregulated by promoter hypermethylation in tumors, and demonstrated that decreased expression of DTX1 in HNSCC tumors maybe associated with NOTCH pathway activation and increased migration potential. 


\section{INTRODUCTION}

As the fifth most common cancer, Head and Neck Squamous Cell Carcinoma (HNSCC) is responsible for 600,000 new cases and over 300,000 deaths per year worldwide $[1,2]$. Nonetheless, the majority of HNSCC patients are diagnosed at an advanced stage due to the asymptomatic course of early stage disease and the absence of the routine screening techniques [3-6]. Development of low toxicity targeted therapeutics and biomarkers for early detection could improve survival rate and quality of life for HNSCC patients.

Traditionally, research groups have focused on the roles of individual genes in HNSCC to develop candidate biomarkers for diagnosis and treatment selection [7]. The process of single-gene investigation is time and labor intensive, while high-throughput profiling enables more rapid discovery of targetable disease-specific modifications. Thus, recent high throughput profiling of HNSCC identified number of targetable disease-specific modifications, such as genetic mutations and differentially expressed genes in HNSCC primary tissues or cell lines compared to normal samples [8-16]. In addition, epigenetic based expression alterations are noted to drive key biologic processes in HNSCC $[17,18]$. Integration of high throughput data from expression and methylation platforms may enhance accurate discovery of cancerdriving genes so they can be used as disease biomarkers or therapy targets [19].

Therefore, a multi-platform high throughput analyses of gene expression and DNA methylation in primary HNSCC and normal samples and outlier statistics [20] were utilized to rank candidate genes and prioritize genes with the most prominent abnormalities in tumor samples that were absent in normal samples. Next, candidate genes were validated in separate clinical cohorts. Finally, the functional role of a lead candidate, DTX1, in HNSCC cell migration was demonstrated. DTX1 expression was found to be increased in samples with decreased NOTCH pathway activity, suggesting that DTXI can serve as a biomarker of NOTCH pathway inhibition. The promoter DNA was exclusively methylated in tumors, suggesting that it can also serve as a HNSCC biomarker. This discovery was made possible due to employment of well-considered statistical approaches, cross cohort validation, and complementary detection tools.

\section{RESULTS}

\section{Candidate genes with differential expression in HNSCC detected by outlier statistics}

In order to identify relevant gene candidates in HNSCC, we used gene expression array data from a discovery cohort of 44 HNSCC primary tumors and 25 non-cancer normal tissue samples described in our previous publications (Supplementary Table 1 and [21-23]). Notably, the clinical differences between tumor and control population of the discovery cohort were identified and discussed earlier [21-24].

The novelty of the current study was that we applied outlier analysis adopted from Ochs et al. [20] to rank and prioritize cancer-related alterations in HNSCC samples relative to normal controls (Figure 1). Outlier analysis is adapted for the study of heterogeneous samples, such as HNSCC primary tissues, because it is sensitive to alterations that maybe present in only a subset of samples. Given the high sensitivity of whole-genome gene expression analysis, thousands of differentially expressed genes can be detected while comparing tumor and normal samples. The heterogeneity of genetic and epigenetic alterations in solid tumors has presented challenges in using conventional statistical approaches, such as $t$-tests or signal-to-noise tests. There are several most-commonly accepted methods employed in cancer research for analysis of high-throughput data of heterogeneous cancers, including Cancer Outlier Profile Analysis (COPA)-based methodology, which compares outliers to an empirical null [25-28]. Outlier-based analysis has provided a mechanism to define significant, but diverse, alterations in cancers [20]. To eliminate low-signal outliers, this work implemented COPA-based statistics with a rank sum outlier approach as well as set a minimum level for the calling of an outlier. Such outlier analysis was recently successfully implemented and validated in a wet-lab setting for the discovery of tumor-specific signatures from DNA methylation array data for HNSCC [29].

Based on the number of outlier samples and the relative signal intensity, 76 of the top ranking candidates were chosen for further analysis (Supplementary Table 2). Overall, 50 candidate genes demonstrated increased gene expression and 26 candidate genes demonstrated decreased gene expression in tumor samples. (Supplementary Table 2). Notably, the standard and more stringent $t$-test demonstrated that 70 out of 76 genes $(92 \%)$ had statistically significant difference in gene expression between normal and tumor samples.

\section{Negative correlation between expression and methylation identifies candidate genes that are epigenetically silenced in HNSCC}

High gene promoter methylation if often associates with decreased gene expression and can result in epigenetic silencing [17, 18]. Therefore, DNA methylation array data was integrated with gene expression analysis (Figure 1) to identify gene expression changes potentially driven by methylation, as well as to eliminate biases from individual high-throughput platform [23]. The Illumina 27 DNA methylation array was utilized, which contained 27,000 probes covering approximately 15,000 genes, including gene promoter probes for 19 of the 
76 candidates. Spearman correlation coefficients were calculated (Supplementary Table 2), and 15 out of 19 genes had negative correlation between expression and methylation. The description of these 15 candidates can be found in Table 1 .

Of the list of 15 candidates, BANK1 (a scaffold protein) and BIN2 (a bridging integrator protein) had the highest combined outlier score and negative Spearman coefficient. DTX1 was chosen for its relatively high outlier score and its regulatory role in the $\mathrm{NOTCH}$ pathway, which is commonly dysregulated in HNSCC [12-14, 22]. All 3 genes have been implicated as potential cancer drivers in other non-head and neck solid tumors [30-33]. Notably, all 3 genes were downregulated and hypermethylated in tumor samples compared to normal controls (Figure 2). Therefore these 3 genes were selected for further validation. Other candidates, such as $C D 79 B$, MAP4K1, GRAP, TNFRSF13C, and INA, had comparable scores and are candidates for further study, as they have also been implicated in carcinogenesis of other cancer types [34-38].

\section{Independent validation of differential expression and methylation of $B A N K 1, B I N 2$ and $D T X 1$}

To confirm the differential expression and methylation of $B A N K 1, B I N 2$ and DTX1, an independent validation cohort was assembled of $61 \mathrm{HNSCC}$ primary tumors and 28 UPPP samples, with similar clinical characteristics as the discovery cohort (Supplementary Table 1). BANK1, BIN2 and DTX1 gene expression was evaluated by qRT-PCR, and DNA methylation was evaluated by bisulfite sequencing (Figure 3, Supplementary Table 3). Gene expression was significantly decreased in tumor tissues for all 3 genes ( $t$-test $p$-values: $9.4 \times 10^{-6}, 7.1 \times 10^{-6}$, and 0.0013 for DTX1, BANK1, and $B I N 2$, respectively), and DNA methylation was present in significantly more tumor samples (Fisher exact test

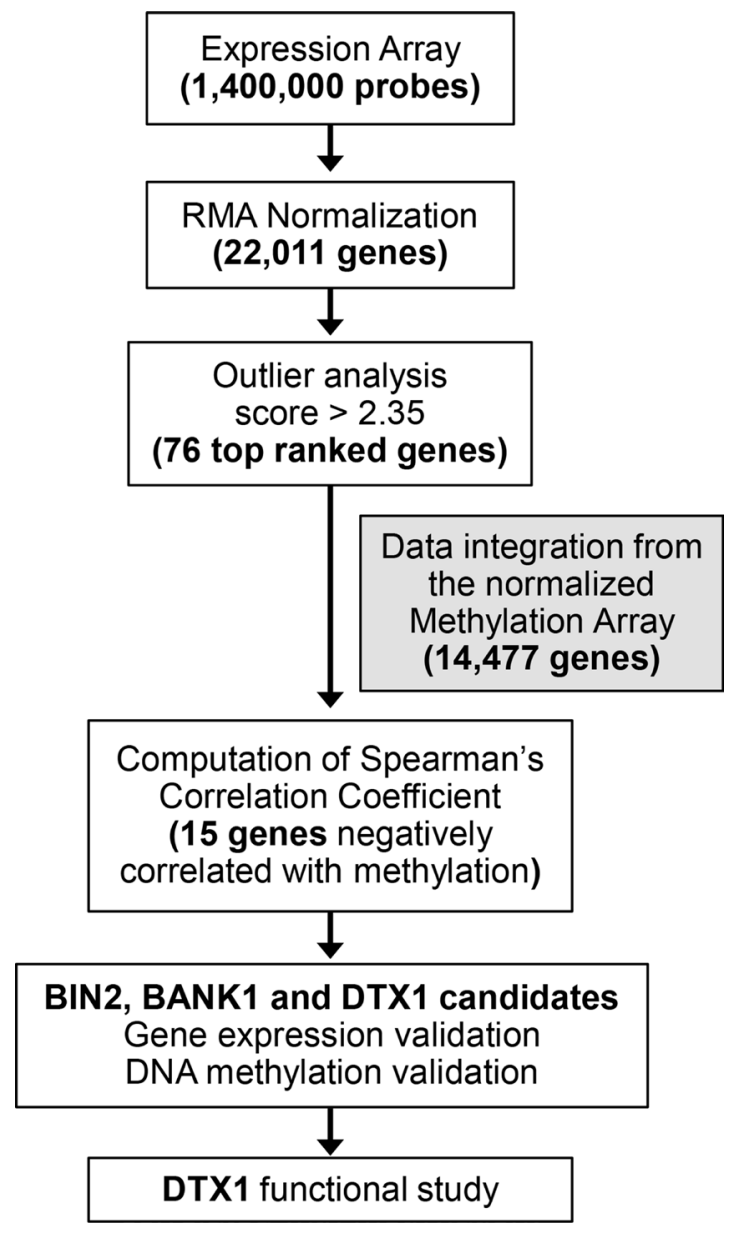

Figure 1: Experimental flow. Expression array probes, 1.4M total, were normalized using RMA package. Gene level estimates were produced by choosing the highest mean expression levels among all probes linked to the same gene for expression, yielding 22,011 genes. We applied outlier analysis [20] to the gene expression data set, containing 22,011 genes. The outlier score cut-off for expression data was set at 2.3, resulting in prioritizing 76 top scoring expression candidates. Spearman gene expression-methylation for these 76 candidates was calculated via integration of normalized methylation array data available for the samples. Fifteen out of 76 candidates were found to have a negative Spearman coefficient. Differential expression and methylation of BIN2, BANK1 and DTX1 were validated in the validation and TCGA-HNSCC cohorts. Functional study was performed for DTX1. 
Table 1: Fifteen candidate genes with negative expression-methylation correlation

\begin{tabular}{|c|c|c|c|c|c|c|}
\hline$\#$ & Gene & Description & $\begin{array}{c}\text { Expression- } \\
\text { Methylation } \\
\text { Correlation, } \\
\text { Spearman } \\
\text { coefficient }\end{array}$ & $\begin{array}{l}\text { Outlier } \\
\text { score }\end{array}$ & $\begin{array}{c}\text { Alteration in different } \\
\text { tumor types }\end{array}$ & Reference \\
\hline 1 & $A T P 2 A 3$ & ATPase & -0.120 & 2.45 & $\begin{array}{l}\text { HNSCC, lung, colon, } \\
\text { cancers of central nervous } \\
\text { system }\end{array}$ & {$[50]$} \\
\hline 2 & ATP8A1 & ATPase & -0.195 & 2.60 & Lung cancer & {$[73]$} \\
\hline 3 & $B A N K 1$ & Scaffold protein & -0.420 & 4.97 & $\begin{array}{l}\text { Lymphoma, colorectal } \\
\text { cancer }\end{array}$ & {$[30,32]$} \\
\hline 4 & BIN2 & Bridging integrator & -0.693 & 2.94 & $\begin{array}{c}\text { myeloproliferative } \\
\text { neoplasm }\end{array}$ & {$[31]$} \\
\hline 5 & $C D 79 B$ & $\begin{array}{l}\text { immunoglobulin-beta } \\
\text { protein }\end{array}$ & -0.556 & 3.16 & Myeloma, CLL & {$[74,75]$} \\
\hline 6 & CYP1B1 & Cytochrome & -0.183 & 2.50 & $\begin{array}{c}\text { Smoking related cancers, } \\
\text { ovarian cancer }\end{array}$ & {$[51,52]$} \\
\hline 7 & DTX1 & Notch-pathway regulator & -0.274 & 3.40 & $\begin{array}{l}\text { thymic tumor, } \\
\text { glioblastoma, } \\
\text { osteoblastoma }\end{array}$ & {$[46,47]$} \\
\hline 8 & FZD3 & Frizzled receptor & -0.161 & 3.02 & $\begin{array}{c}\text { Colorectal, non-melanoma } \\
\text { skin cancer, CLL }\end{array}$ & {$[53-55]$} \\
\hline 9 & $G R A P$ & $\begin{array}{c}\text { cytoplasmic signaling } \\
\text { protein }\end{array}$ & -0.444 & 2.93 & $\begin{array}{l}\text { medullary thyroid } \\
\text { carcinoma }\end{array}$ & {$[34]$} \\
\hline 10 & INA & Neurofilament & -0.333 & 2.69 & $\begin{array}{l}\text { colorectal cancer, } \\
\text { adenomas }\end{array}$ & {$[35]$} \\
\hline 11 & $M A P 4 K 1$ & MAP kinase & -0.590 & 2.58 & Bladder, colorectal cancer & {$[36,38]$} \\
\hline 12 & ORAOV1 & Oral cavity oncogene & -0.064 & 4.00 & oral SCC & {$[56]$} \\
\hline 13 & PDE5A & phosphodiesterase & -0.10 & 3.51 & melanoma & {$[76]$} \\
\hline 14 & TNFRSF $13 C$ & TNF receptor & -0.295 & 3.12 & non-Hodgkin lymphoma & {$[37]$} \\
\hline 15 & $V A V 1$ & $\begin{array}{c}\text { proto-oncogene, a member } \\
\text { of guanine nucleotide } \\
\text { exchange factors }\end{array}$ & -0.208 & 2.64 & $\begin{array}{c}\text { neuroblastoma, lung, } \\
\text { pancreatic cancer }\end{array}$ & {$[77,78]$} \\
\hline
\end{tabular}

Genes are in alphabetic order. Spearman coefficient and Outlier score are provided.

p-values: $0.105,<0.0001$, and 0.0006 for DTX1, BANK1, and $B I N 2$, respectively). Utilization of the independent cohort of HNSCC samples analyzed by complementary methodology (Figure 3) enhanced the rigor of the data through technical validation and eliminated potential sample biases. Notably, for DTX1 differential methylation did not reach statistical significance $(p=0.105)$. However, $D T X 1$ showed almost no methylation in normal tissues, resulting in high tumor specificity. Therefore, DTX1 was maintained as a gene candidate for further study.

High throughput gene expression and DNA methylation analysis was also recently performed by TCGA (The Cancer Genome Atlas), including 222 matched HNSCC tumors and 50 normal samples (Supplementary Table 1 and [39]). TCGA used RNASeq for gene expression evaluation and Illumina Infinium
HumanMethylation450 BeadChip platform for DNA methylation analysis. We used the TCGA dataset for $B A N K 1, B I N 2$ and DTX1 validation (Figure 4). TCGA was not used for initial discovery because use of adjacent normal tissue from cancer patients was a concern. In the HNSCC population, high rate of tobacco and alcohol exposure lead to field of cancerization effect, as well as genetic and epigenetic changes can be seen in tumor adjacent apparently normal tissue [40, 41].

Nonetheless, data from TCGA was able to provide additional independent validation. Within TCGA, DTX1 was found to have significantly decreased expression $\left(p\right.$-value $\left.=8 \times 10^{-6}\right)$ and promoter hypermethylation $\left(p\right.$-value $\left.=3.11 \times 10^{-20}\right)$, validating prior results. However $B A N K 1$ shared promoter hypermethylation $\left(p\right.$-value $\left.=6.36 \times 10^{-19}\right)$ without significant changes in 
gene expression $(p$-value $=0.38)$. For BIN2 neither gene expression downregulation nor hypermethylation changes were validated in TCGA. Since DTX1 showed the best performance in TCGA cross validation, we focused our further functional validation only on the DTX1 gene.

\section{The role of DTX1 in the NOTCH pathway for HNSCC}

DTX1 is a regulator of the NOTCH pathway $[42,43]$. Since the NOTCH pathway is dysregulated in HNSCC $[12,13,22]$, we evaluated the role of DTX1 relative to other NOTCH pathway genes (KEGG database and [22]). Overall, we analyzed gene expression for 44 $\mathrm{NOTCH}$ related genes for $44 \mathrm{HNSCC}$ and 25 normal controls from the discovery cohort using Affymetrix Exon
Array data (Supplementary Figure 1). Genes were sorted by unsupervised hierarchical clustering. DTX1 was noted to cluster together with $D T X 3$ (NOTCH regulator), $M F N G$ (NOTCH modifier) and DLL3 (NOTCH ligand).

Interestingly, separation of HNSCC samples by DTX1 expression separated the tumor samples into two subsets of samples, with different expression of NOTCH pathway genes in each group (Supplementary Figure 1). To confirm this observation, we separated 44 tumors into two equal groups by DTX1 expression: lower DTX1 expression $(n=22)$ and higher DTX1 expression $(n=22)$ and compared the expression of NOTCH genes in each group (Supplementary Table 4). Indeed, 34 out of 43 NOTCH pathway genes excluding DTX1 (79\%) were significantly differentially expressed between $D T X 1$ low and high expressed tumors. According to Supplementary
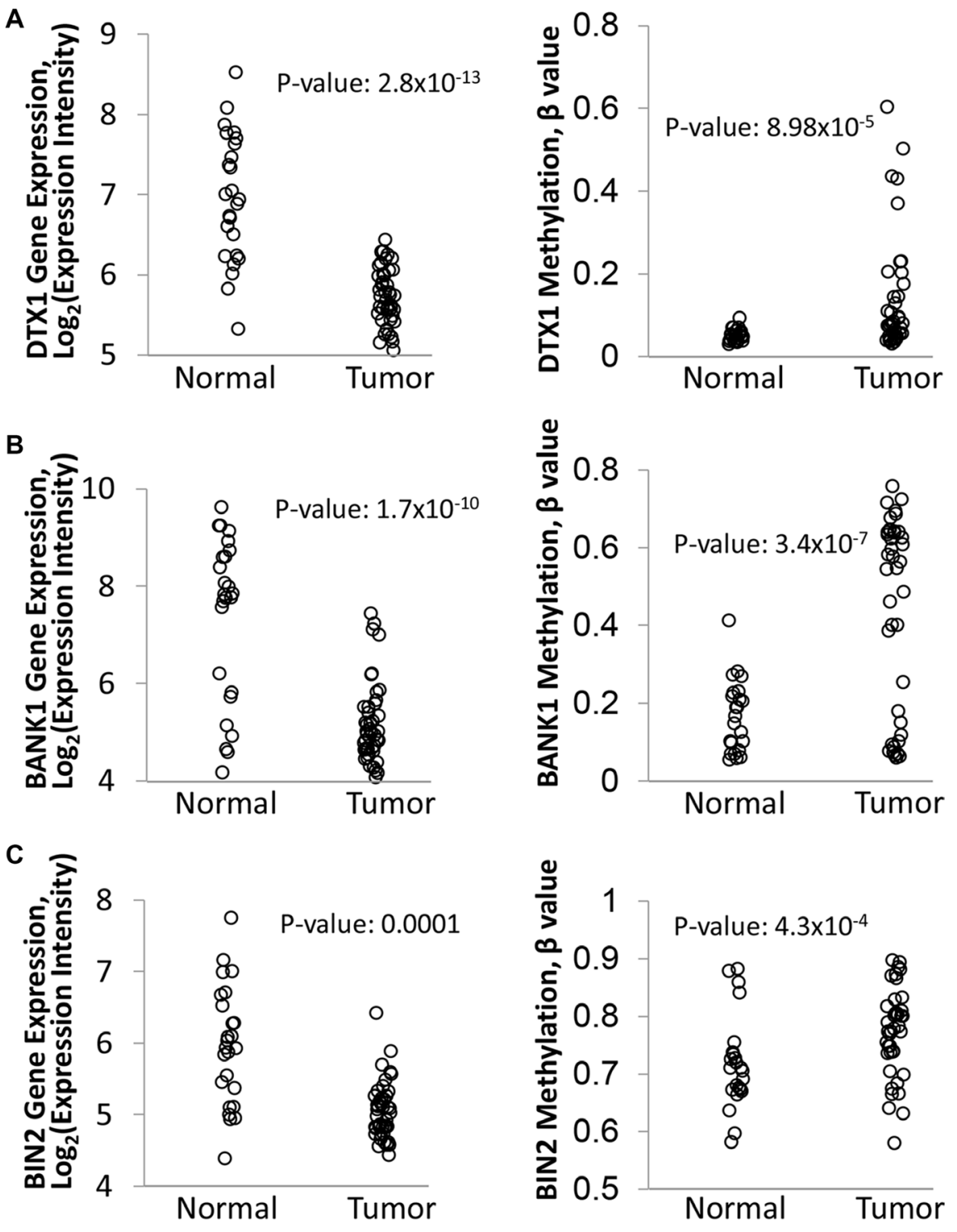

Figure 2: Differential expression and methylation of DTX1 (A), BANK1 (B) and BIN2 (C) in the original discovery cohort. Gene expression (left) was evaluated by Affimetrix HuEx1.0 GeneChip. DNA methylation (right) was evaluated by Illumina Infinium HumanMethylation27 BeadChip platform, and the data was normalized and processed as described in methods. $P$-value were calculated by $t$-test. 
Figure 1 and Supplementary Table 4, the majority of NOTCH pathway genes were significantly upregulated in the group of samples with lower DTX1 expression ( $n=28$ genes, including NOTCH1-3, HES1, HEY1, and $J A G 1)$ relative to $D T X 1$ high expression samples. Fifteen genes had lower expression in the DTX1 lower-expression group relative to $D T X 1$ high expression samples, including DLLs, DTXs and NOTCH4 genes. Gene set analysis confirmed that the set of NOTCH pathway genes were significantly overexpressed in DTX1 low samples relative to $D T X 1$ high ( $p$-value of 0.0012 , Supplementary Figure 2 ) and relative to Normal samples ( $p$-value of 0.0024 , Supplementary Figure 2). These findings confirm that downregulation of $D T X 1$ results in a strong difference in activation of the NOTCH pathway in HNSCC samples.

We further evaluated relative expression of DTXI with NOTCH downstream targets (Supplementary Figure 3). DTXI expression co-clustered with the expression of GATA4 (regulated by HEY1) [44] and NEUROG3 (negatively regulated by HES1) [45] by unsupervised hierarchical clustering. The set of $\mathrm{NOTCH}$ downstream targets were not significantly differentially expressed between $D T X 1$ sample groups or relative to normal samples with gene set analysis. Nonetheless, GATA4 and NEUROG3 were all downregulated in samples with low $D T X 1$ expression relative to high $D T X 1$ expression ( $p$-values of $7 \times 10^{-7}$ and $6 \times 10^{-10}$, respectively; Supplementary Table 5). In addition, DTX1 low samples had significantly higher expression of HES1 relative to DTX1 high samples ( $p$-value of 0.01; Supplementary Table 5), consistent with NEUROG3 downregulation [45], but significant changes were not observed from gene set statistics (data not shown).

\section{Functional role of DTX1 dysregulation in HNSCC}

Since DTX1 was downregulated in HNSCC tumor samples, (Figures 2-4) it is expected to have tumorsuppressor properties. Overexpression and silencing of DTX1 expression in vitro did not affect cell proliferation (3 immortalized normal keratinocyte and 6 HNSCC cell lines were tested, data not shown). On the other hand, recent data suggest that $D T X 1$ may play a role in inhibition of invasion in osteosarcoma [33]. In order to evaluate if DTX1 could modify the invasiveness of HNSCC cells as well, we performed matrigel cell migration assays. UMSCC-047 and UM-SCC-22B were selected due to their increased mobility relative to other HNSCC cell lines necessary for invasion assay. Base-line DTX1 expression analysis determined that UM-SCC-047 had relatively lower gene expression and, therefore, was used for ectopic DTX1 expression (Supplementary Figure 4A). On the other hand, UM-SCC-22B had a higher DTX1 expression rate and, therefore, was used for knock-down RNAi experiments. Upregulation of $D T X 1$ via ectopic expression leaded to significant decrease of UM-SCC-047 cell invasion ( $p=0.014$, Figure 5A and Supplementary Figure $5 \mathrm{~A}$ ), while downregulation of DTX1 by RNAi leaded to strong enhancement of cell invasiveness in UM-SCC-22B cell line $(p=0.004$, Figure 5B and Supplementary Figure Supplementary 5B).

\section{DISCUSSION}

Five year survival for HNSCC is only $50 \%$, and there is a clear need for identification of novel cancer-
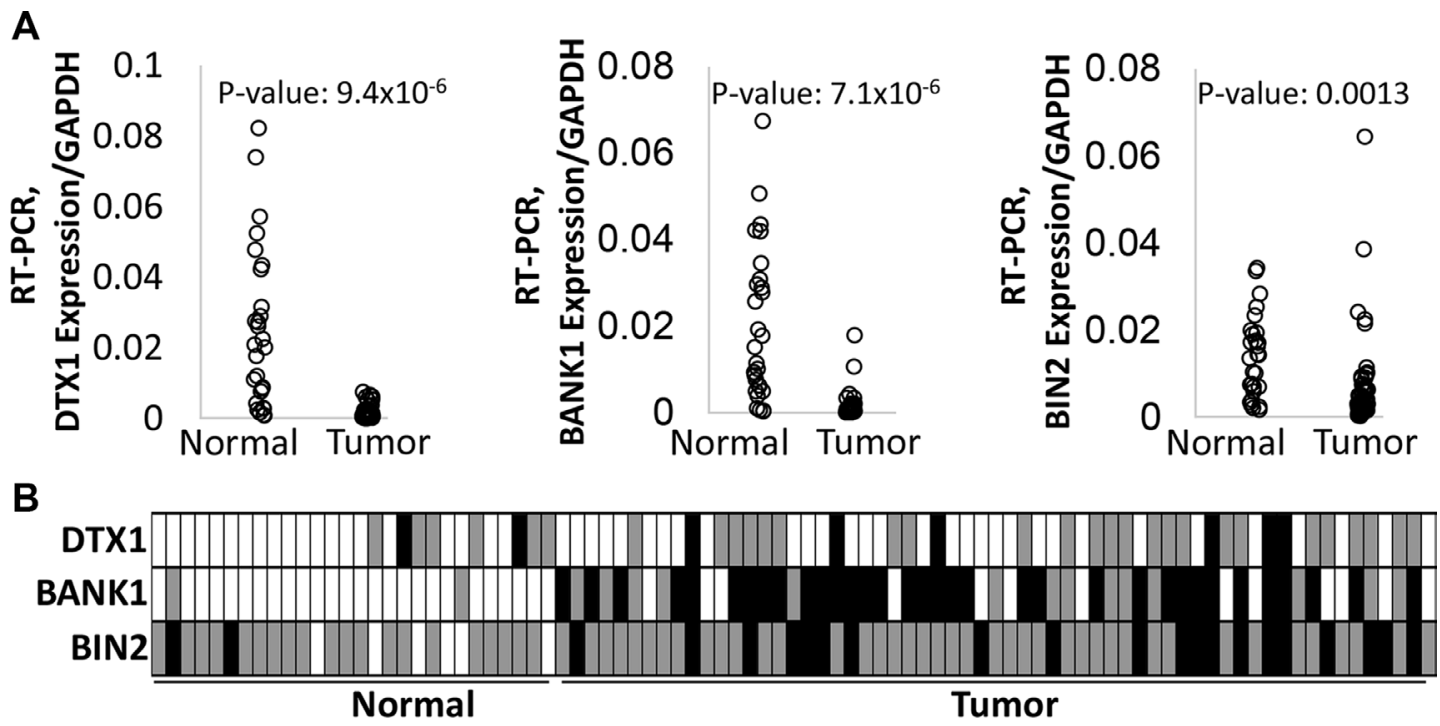

Figure 3: Differential expression and methylation of $D T X 1, B A N K 1$ and $B I N 2$ in the validation cohort. Gene expression (A) was evaluated by quantitative RT-PCR. $P$-values were calculated by $t$-test. DNA methylation (B) was evaluated by bisulfite sequencing. Box color-code: white-unmethylated (hypomethylated); grey-hemimethylated, black-hypermethylated. $P$-values were calculated by Fisher exact test, as unmethylated signal vs methylated signal (hemi- or hypermethylated) in two groups. $P$-values for $D T X 1=0.105$, for $B A N K 1<0.0001$, for $B I N 1=0.0006$. 
specific therapeutic targets. This study integrated DNA methylation and gene expression to define cancerrelated alterations. We performed genomic analysis with thorough confirmatory and functional validation, which identified DTX1 as a potential regulator of migration in HNSCC.

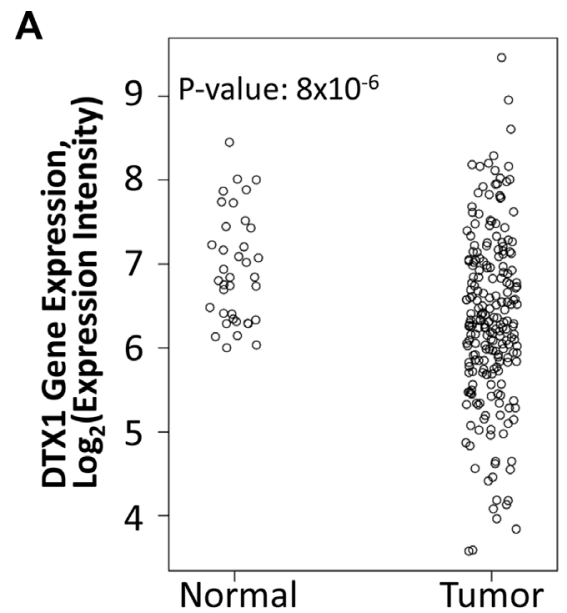

B

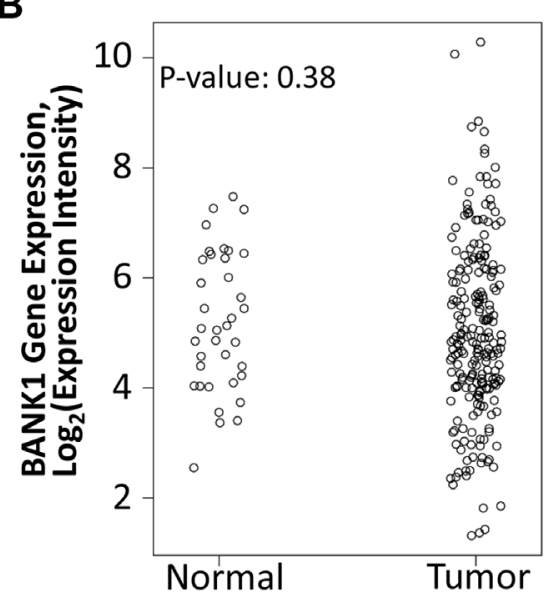

C

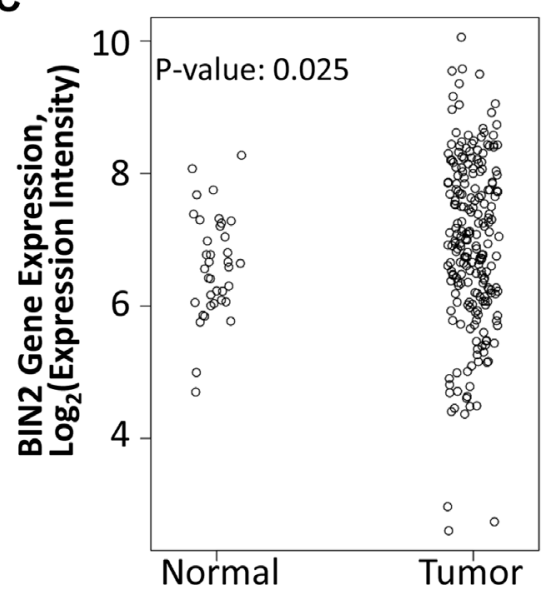

The integrated analysis and outlier statistics allowed us to correlate gene expression with promoter methylation and discriminate candidates that were biologically relevant. Indeed, all 15 high-value candidates identified through these methods (Table 1) have been described as cancer drivers in other cancer types. Thus, DTX1
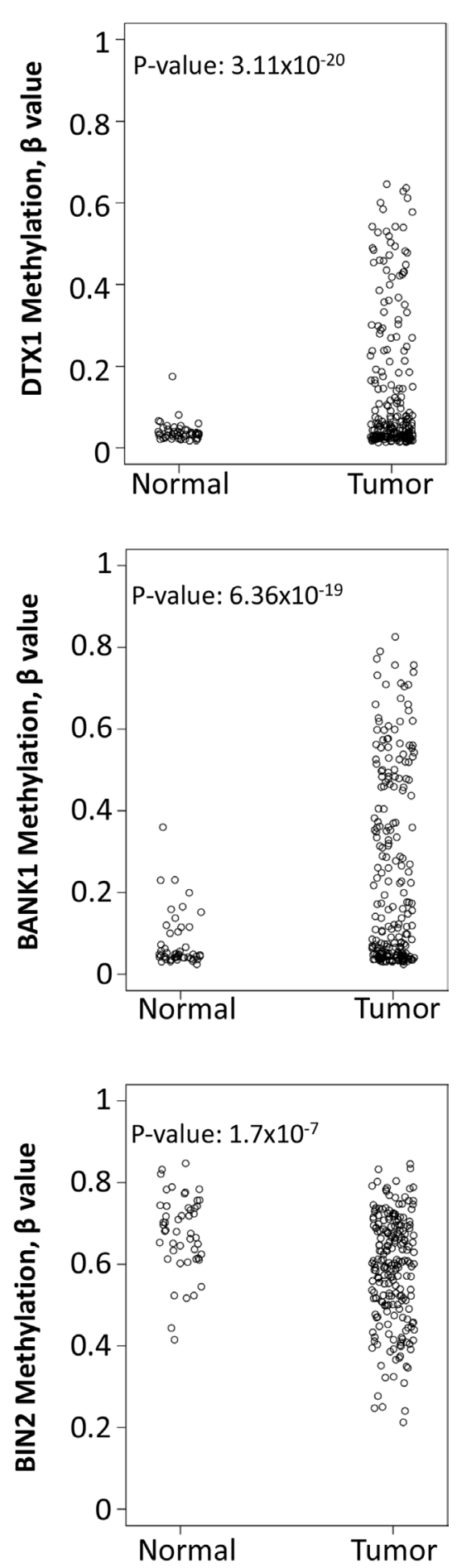

Figure 4: Differential expression and methylation of DTX1 (A), BANK1 (B) and BIN2 (C) in the TCGA-HNSCC cohort. Gene expression (left) was evaluated by RNA-Seq. DNA methylation (right) was evaluated by Illumina Infinium HumanMethylation 450 BeadChip platform, and the data was normalized and processed as described in methods. $P$-values were calculated by $t$-test. 
is a regulator of the NOTCH pathway; this pathway was recently found both downregulated in HNSCC via NOTCH1 mutations and upregulated in HNSCC via amplifications of NOTCH's ligands and receptors $[12-14,22]$. DTX1 is upregulated in thymic tumors and in glioblastoma [46, 47], and it inhibits osteoblastoma cell invasion [33]. Moreover, multiple DTX1 polymorphisms were found in non-small cell lung and B-cell precursor acute lymphoblastic leukemia patients [48, 49], which most likely associate with inactivation of DTX1 and further NOTCH activation in these cancers. BANK1 is downregulated in lymphoma and colorectal cancers $[30,32]$. Overexpressed BIN2 fusions were detected in myeloproliferative neoplasms [31]. Out of other candidates, ATP $2 A 3$ has been shown to be mutated and downregulated in HNSCC, lung, colon and central nervous system cancers [50]. Several polymorphism of CYP1B1 are found in many cancer types, including tobaccorelated cancers; $C Y P 1 B 1$ is also overexpressed in ovarian cancer [51, 52]. Wnt-pathway receptor FZD3 is strongly expressed in colorectal and non-melanoma skin cancer and during chronic lymphocytic leukemia, CLL [53-55]. ORAOV1 is an overexpressed marker of oral SCC [56]. Information about other genes can be found in Table 1.

In order to confirm the role of identified candidate genes, the 3 candidates were independently validated in multiple cohorts. As acknowledged by Mirghani et al [57], high throughput data is often poorly validated, with biases inherent to a single institution cohort or single methodology. To improve the candidate discovery pipeline, we employed both single-institution and multiinstitutional HNSCC cohorts, and utilized diverse detection platforms: Illumina exon array, RNA-Seq and qRT-PCR for gene expression; and Methylation arrays
27 and 450, as well as bisulfite sequencing for DNA methylation. Moreover the 3 genes were confirmed to be hypomethylated and upregulated in healthy tissues of noncancer patients and in non-cancer tumor-adjacent tissues of HNSCC patients with minor exclusions. While only 3 exemplary candidate genes out of the total 15 candidates were evaluated, the others may be expected to have strong differential expression and methylation in HNSCC regardless of sample cohort and detection tool.

Analysis of gene expression of NOTCH pathway members suggested that DTX1 downregulation in HNSCC is correlated with downregulation of some $\mathrm{NOTCH}$ pathway genes including $D T X 3, D L L 3$, and $M F N G$, as well as genes downstream of NOTCH (NEUROG3 and GATA4). Furthermore, DTX1 expression was inversely correlated with HES1 expression. These results confirm prior data that HES1 is a negative regulator of NEUROG3 and $D T X$ s expression $[33,45]$. DTX1 carries a putative SH3-binding domain and binds to the intracellular domain of NOTCH (ICN) [42]. One mechanism by which DTX1 may negatively regulate NOTCH is through ubiquitination; DTX1 may be an E3 ubiquitin ligase, as it contains a RING finger and two WWE domains [58]. Zhang and colleagues [33] proposed that DTX1 may bind and ubiqutiniate NOTCH's ICN, leading to negative regulation of NOTCH pathway, which was consistent with our findings (Supplementary Figure S6). HEY1 also negatively regulates GATA4 [44], which was downregulated in parallel with DTX1.

Overall, DTX1 was downregulated in the entire HNSCC discovery cohort, together with 20 other NOTCH pathway genes including DLLs, NOTCH1, NOTCH2 and NOTCH4 (Supplementary Table 4). JAG1, JAG2, $H E Y 1$ and HES1 had relatively higher expression in
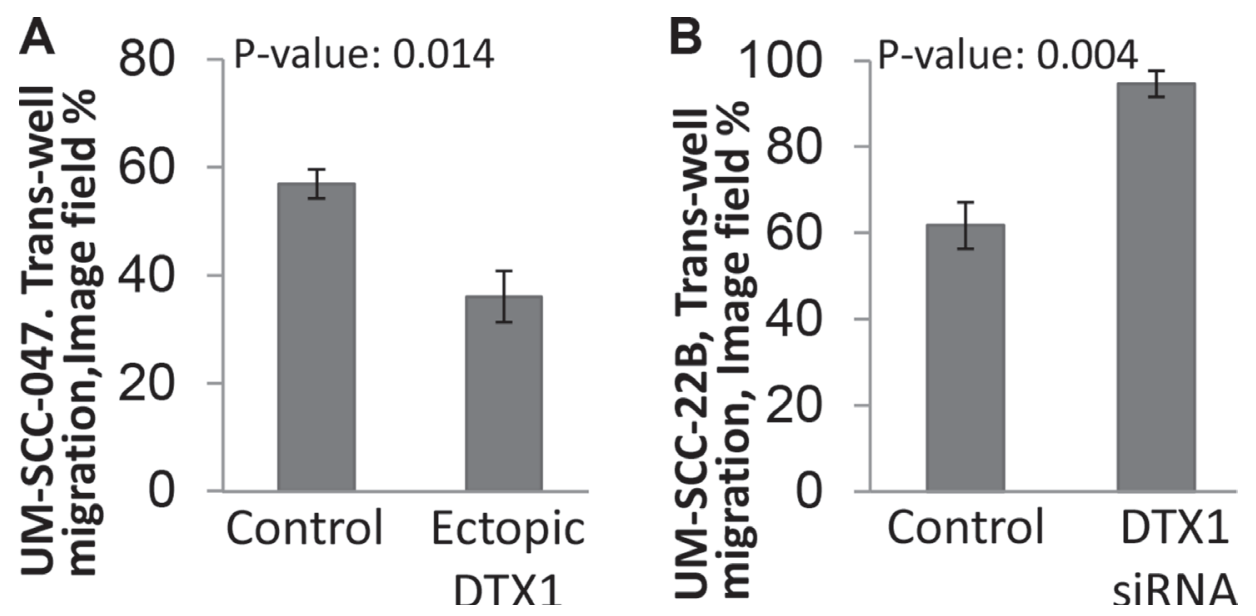

Figure 5: DTX1 blocks HNSCC invasiveness. Migration assay was performed using UM-SCC-047 (A) or UM-SCC-22B (B) cells using transient transfection. The image of cells that had invaded through matrigel (Supplementary Figure 5) was processed and quantified in Photoshop. Both UM-SCC-047 and UM-SCC-22B cells had similar 60\% invasion when treated with control constructs (empty vector for ectopic expression or non-targeting siRNA pool for RNAi). The migration of each cell was dysregulated significantly by ectopic DTX1 overexpression ( $a$, UM-SCC-047 cells) or by transient $D T X 1$ downregulation ( $b$, UM-SCC-22B cells). $P$-value were calculated by $t$-test for experiments performed in triplicate. Transfection efficiency for each experiment was confirmed by qRT-PCR (Supplementary Figure 4). 
tumor samples compared to the pool of normal controls (Supplementary Table 4). This data suggested that DTX1 expression can serve as biomarker of NOTCH pathway inhibition. While the NOTCH pathway is activated in many cancer types, DTX1 is seen to be downregulated in osteoblastoma and HNSCC, while it is upregulated in glioblastoma [22, 33, 46, 59]. In addition, the NOTCH pathway was also found to be downregulated in thyroid cancer and in subgroup of HNSCC patients $[22,60]$. Notably, genetic alterations of NOTCH1 were recently found to dysregulate the $\mathrm{NOTCH}$ pathway in HNSCC $[12,13]$. However, we did not find any correlation of DTX1 expression with presence of NOTCH1 mutations $[14,22,61,62]$. Interestingly, 1/3 of $\mathrm{NOTCH}$ pathway genes are co-downregulated with DTX1 (such as DLLs, DTXs, and NOTCH4), while the rest of the NOTCH pathway genes were upregulated in the low DTX1 expression subgroup (genes including NOTCH1-3, HES1, HEY1, and JAG1, Supplementary Tables 4-5). These results correlate with recent discovery that NOTCH pathway has complex gene interactions and dual function, where it is activated in some tumors while inactivated in others [22, 61]. Notably, there were more HPV-related $(\mathrm{HPV}+)$ patients in the lower DTX1 expression group ( $n=9 \mathrm{HPV}+$ patients), compared to the higher DTX1 expression group $(n=4 \mathrm{HPV}+$ patients, Fisher's exact test $p$-value $=0.185)$. There were 4 times more oral cavity patients in the higher DTX1 expression group ( $n$ $=8,0.069$ ). Unfortunately, those or other correlations with clinical characteristics did not reach statistical significance. This is the first report that has demonstrated that DTX1 blocks HNSCC migration, which is in agreement with recently published data suggesting that DTX1 blocks osteosarcoma invasiveness [33]. Results of current analysis suggests that in HNSCC, downregulation of DTX1 by DNA methylation leads to more aggressive behavior of HNSCC cells.

Since the expression of NEUROG3 and GATA4 (downstream of HES1 and HEY1 respectively) was downregulated in parallel with $D T X 1$, we speculate, that NEUROG3 and GATA4 have a negative effect on cell migration (Supplementary Figure 6). The molecular mechanism by which DTX1 blocks HNSCC cell migration needs to be further evaluated. Additional analysis of role of DTX1 on cell proliferation did not show any significant changes of cell growth depending of DTX1 expression (data not shown).

We have to acknowledge several limitations of our study: 1) clinical characteristics between tumor and nontumor groups do not match in patients in both discovery and validation cohorts (Supplementary Table 1), due to peculiarity of UPPP and HNSCC populations [21-24]. Nonetheless the employed UPPP population helped revealing strong cancer-specific signatures of HNSCC in previous studies [21-24]. Moreover, employment of TCGA's control population with matched clinical characteristics confirmed our original discovery of hypermethylation and downregulation of candidate genes, especially the leading candidate, $D T X 1$, in tumor samples. 2) Utilization of older generation DNA methylation array data (Illumina Infinium HumanMethylation27 BeadChip) narrowed down the list of candidates by lack of available promoter-methylation data for several genes. Nonetheless this is one of the largest HNSCC cohorts, after the employed TCGA, with publicly available matched gene expression and promoter methylation data [21-24]. We see this study as confirmation of our pipeline for discovery of biologically-relevant candidates and smaller number of candidate genes helped us focus only on the limited number of genes within a limited time frame. 3) Not all candidates were functionally evaluated within given time frame, but will be used for further independent analyses. The complete list of high priority candidates discovered during this project will become available for the research community for their prospective studies.

Thousands of alterations can be detected by different independent high throughput platforms, given their high sensitivity. Integration of gene expression and DNA methylation high throughput data focused study to a limited list of relevant genes with potential roles in HNSCC carcinogenesis. Employment of well-considered statistical approaches, cross cohort validation, and complementary detection tools allowed us to discover an epigenetically regulated tumor suppressor gene, DTX1, which controls HNSCC cell migration.

\section{MATERIALS AND METHODS}

\section{Specimen cohort assembly}

We used two independent cohorts of specimens, each composed of primary head and neck squamous cell carcinoma (HNSCC) tissue specimens and control specimens comprising normal mucosal samples from uvulopalatopharyngoplasty (UPPP) surgeries of noncancer affected patients. The discovery cohort comprised of 44 HNSCC and 25 normal UPPP samples, as described in previous publications $[22,23]$. The validation cohort comprised of $61 \mathrm{HNSCC}$ and 28 normal UPPP samples, is reported for the first time. The demographic and clinicopathological characteristics of patients from the discovery and validation cohorts are listed in Supplementary Table 1. The clinical differences between tumor and control populations in the discovery cohort were previously identified and acknowledged [21-24].

All tissue samples were obtained from the Johns Hopkins Tissue Core, as a part of the Head and Neck Cancer Specialized Program of Research Excellence (HNC-SPORE). These samples were acquired under Internal Review Board-approved research protocol 
\#NA_00036235. Informed consent was obtained from all patients recruited under this protocol prior to participation in the study.

\section{Tissue processing}

Two Johns Hopkins Hospital Pathologists (WHW and JAB) independently confirmed that all primary tumor samples were consistent with HNSCC. After this, all tumor tissues were microdissected to yield at least $80 \%$ tumor purity. All tissue specimens were stored at $-140^{\circ} \mathrm{C}$ until a cut and extraction were performed. For each extraction, a $0.35 \mathrm{~mm}$ thick cut of tissue was used.

\section{RNA preparation}

RNA was isolated from $0.35 \mathrm{~mm}$ thick frozen tissue cuts with the mirVana miRNA Isolation Kit (Ambion, Forster City, CA) at room temperature as per manufacturer's recommendations. The concentration of the isolated RNA was quantified using the NanoDrop spectrophotometer (Thermo Fisher Scientific, Waltham, MA).

\section{DNA preparation}

Similarly, $0.35 \mathrm{~mm}$ thick frozen tissue cuts were digested in 1\% SDS (Sigma-Aldrich, St. Louis, MO) and $50 \mu \mathrm{g} / \mathrm{ml}$ proteinase $\mathrm{K}$ (Invitrogen, Carlsbad, CA) solution at $48^{\circ} \mathrm{C}$ for 48 hours. The DNA was purified by phenol-chloroform extraction and ethanol precipitation as previously described [63]. DNA was resuspended in LoTE buffer, and the DNA concentration was quantified using the NanoDrop spectrophotometer.

\section{High throughput transcriptional and methylation profiling data}

High throughput data of gene expression and DNA methylation was obtained from the discovery cohort which was previously published using the methods described previously $[22,23]$. The gene expression data for the discovery cohort was obtained from Affymetrix HuEx1.0 GeneChips (containing 1.4 million probes) and is available on the NCBI Gene Expression Omnibus (GEO) public repository (GEO33205). DNA methylation data for the discovery cohort was obtained using Illumina Infinium HumanMethylation27 BeadChip (probing 27,578 CpG dinucleotides) is also publically available (GEO33202). The data from both platforms can be downloaded from the combined superSeries GSE33232.

\section{Reverse transcription and quantitative real time PCR}

Validation of gene expression was performed in the independent validation cohort using reverse transcription and quantitative real-time PCR. One microgram of RNA from each sample in the validation cohort was reverse transcribed using the High Capacity cDNA Reverse Transcription Kit (Applied Biosystems, Forster City, CA). Quantitative real-time PCR (qRT-PCR) was performed using gene-specific expression assays (Supplementary Table 3) and Universal PCR Master Mix on a 7900HT real-time PCR machine (Applied Biosystems) as per manufacturer's recommendations. Expression of the gene of interest was quantified in triplicate relative to $G A P D H$ expression using the 2- $\Delta \Delta \mathrm{CT}$ method [64]. We also confirmed that $G A P D H$ expression was not significantly different in normal and HNSCC samples.

\section{Bisulfite treatment and bisulfite genomic sequencing}

Validation of DNA methylation was performed in the validation cohort through bisulfite genomic sequencing. The EpiTect Bisulfite Kit (Qiagen, Valencia, CA) was used to convert unmethylated cytosines to uracil in genomic DNA. Touch-down PCR was performed on bisulfite-converted DNA with primers designed to span areas of $\mathrm{CpG}$ islands for each gene promoter (Supplementary Table 3). - [65]. The PCR products were purified using the QIAquick 96 PCR Purification Kit (Qiagen). The purified PCR product from bisulfiteconverted DNA for each sample and gene was sequenced (Genewiz, South Plainfield, NJ). Relative heights of C and $\mathrm{T}$ peaks measured on sequencing were then used to assign the DNA methylation status as unmethylated, methylated or hemimethylated.

\section{TCGA sample selection}

The TCGA project for HNSCC was recently completed and published [39]. Overall, the analysis included $n=279$ HNSCC samples. Such a cohort was different from the employed Johns Hopkins cohorts by increased number of oral cavity samples, samples with TNM stage II-III, and decreased HPV-positive samples. In order to "match" clinical characteristics of the analyzed TCGA cohort, we removed oral cavity samples with TNM stage II and III. We did not do any additional manipulation of the TCGA cohort to keep the "matching" procedure simple and randomized, as well as to avoid any potential biases due to non-random sample selection. Since oral cavity samples are predominately HPV-negative, this helped to increase relative percentage of HPV-positive HNSCC samples within the new "matched" TCGA population ( $n=222$ total). Notably, the new "matched" TCGA cohort did not significantly change other clinical characteristics that were relevant to the Johns Hopkins cohort. This "matched" TCGA cohort (Supplementary Table 1) was used for validation purposes (Figure 4). 


\section{Cell culture}

\section{Cell lines and cell culture conditions}

Human HNSCC cell lines UM-SCC-047 and UMSCC-22B were provided by Dr. Thomas Carey (University of Michigan) for the functional experiments. Each cell line was authenticated using a Short Tandem Repeat (STR) Identifiler kit (Applied Biosystems). Cells were grown on high-glucose DMEM media (Clontech, Mountain View, CA), supplemented by $10 \%$ fetal bovine serum (FBS) and $1 \%$ Penicillin-Streptomycin at $37^{\circ} \mathrm{C}$ in $5 \% \mathrm{CO}_{2}$.

\section{Transient transfection}

For knockdown assays, the expression of DTX1 gene was downregulated by ON-TARGETplus siRNA SMARTpool RNA (L-006525-00-0005, Thermo Scientific, Waltham, MA) using RNAiMAX transfection reagent (Life Technologies, Carlsbad, CA). Non-targeting SMARTpool RNA (D-001810-10-05, Life Technologies) was used as a control. The transfection efficiency was confirmed by qRT-PCR.

The ectopic overexpression of DTX1 was achieved with pCMV6-Entry-DTX1 plasmid (RC208338, Origene, Rockville, MD) using FuGENE Extreme 9 transfection reagent (Roche, Nutley, NJ). Empty pCMV6-Entry (PS100001, Origene) was used as a control. Transfection efficiency was confirmed by DTX1-specific qRT-PCR using the same qRT-PCR technique as described earlier for tissue RNA analysis.

\section{Matrigel invasion assay}

We performed the Matrigel invasion assay to assess the migration and invasion ability of transfected cells with over expression and under expression of DTX1 using techniques described in previous publications [66]. In short, $8-\mu \mathrm{m}$ pore filter inserts in 24-well plates (SigmaAldrich) coated with Matrigel (BD Biosciences, San Jose, CA) was used. Cells were transfected for 24 hours and then were trypsinized, washed three times with serum-free DMEM media and resuspended in serum-free DMEM to obtain the concentration of $10^{6}$ cells $/ \mathrm{ml}$. An aliquot of 100 $\mu 1$ of cells were plated onto each insert. Chemo-attractant media with $10 \%$ FBS $(600 \mu \mathrm{l})$ was added to the bottom of a 24-well plate. Each insert, with cell suspensions, was placed into the individual well with chemo-attractant media. After 24 hours of incubation at $37^{\circ} \mathrm{C}$ in $5 \% \mathrm{CO}_{2}$, the inserts were removed from the media. Cells on the upper surface of the insert that did not invade through the membrane were removed with a cotton swab. The cells that had migrated to the lower surface of the membrane, facing the chemo-attractant media, were fixed by $10 \%$ formaldehyde and stained by $1 \%$ crystal violet. The membranes with fixed and stained cells were removed, mounted onto slides and photographed by microscopy at $4 \times$ magnification. Each experiment was performed in triplicate.

\section{Matrigel migration quantification}

The $4 \times$ magnified images of the insert membrane were analyzed using Adobe Photoshop SC6 (Adobe Systems, McLean, VA). Stained cell-occupied image area (purple) was selected by the "Color Range" tool with 70\% fuzziness. The number of pixels in the entire image and the number of pixels within areas occupied by cells were calculated by the "Histogram" tool of Photoshop. The percentage of image field occupied by cells was calculated as total number of pixels occupied by cells relative to the total number of pixels. Triplicate images were analyzed for each experiment and the mean of percentage of the cell-occupied image field was calculated.

\section{Statistical analysis}

\section{Expression array normalization}

The gene expression data from GEO33205 used Robust Multiarray Average (RMA) implemented in the Bioconductor oligo package $[67,68]$ for normalization, as previously described $[21,22]$. The gene level expression estimates were calculated as the mean expression levels among all core probes linked to the same gene, yielding 22,011 genes.

\section{DNA methylation array normalization}

For promoter methylation data available at GEO33202, beta values (percent methylation) were estimated from unmethylated (U) and methylated (M) measurements on a probe level basis: $\beta=\mathrm{M} /(\mathrm{M}+\mathrm{U})$ $[23,24]$. The gene level estimates were produced by choosing the highest methylation levels among all probes linked to the same gene yielding, 14,477 individual genes.

\section{Outlier analysis}

HNSCC is a heterogeneous disease with cancerrelated changes detected in only a small portion of the samples [12-14, 39]. Unfortunately, such changes are poorly detected by conventional statistical approaches such as the $t$-test. A standard method employed in cancer research for outlier analysis is Cancer Outlier Profile Analysis (COPA) and its derivatives [28, 69], which generate statistics by comparing the outlier distributions to an empirical null generated by permutation of class labels. However, these methods have limitations when counting outliers since the distribution of medians and median absolute deviations permits outliers to be called in cases where the deviations are biologically insignificant. Therefore, we recently implemented a rank sum outlier approach, modified from Ghosh [70], where a minimum change levels was set for the calling of an outlier [20]. Such methods allowed us to eliminate many outliers where change is not biologically meaningful (e.g., a gene expression change of less than $10 \%$, or $2.35 \log$ fold change, between any two samples). The outlier statistics was used exclusively for discovery purposes. 
To discover the genes with changes in expression, we applied the outlier statistics described above in reference [20] to the array gene expression data set, containing the 22,011 genes for each of 44 HNSCC tissue samples from the discovery cohort. The signals from 25 normal samples from the same cohort were used to establish the empirical null level for each gene. We calculated outlier score for both left-tail (10th percentile) and right-tail (90th percentile) cases, which allowed us to define outliers that were downregulated and upregulated, respectively $[20,70]$. The outlier statistics yielded an outlier score, which quantified the number of tumors with gene expression values that were outliers from the distribution defined by normal as defined in previously published work [20]. Each of the 22,011 genes was assigned its outlier score and ranked from the largest to the smallest. Outlier analysis does not have a cut-off value of significance, such as 0.05 for $p$-value; therefore for the convenience we manually selected the genes with the top 76 outlier scores as candidates (manual outlier score cut-off set $=2.3$, Supplementary Table 2). All outlier analyses were performed with custom scripts in R adapted from [20].

\section{The pathway enrichment analysis}

The pathway enrichment analysis utilized gene expression data was used for $43 \mathrm{NOTCH}$ pathway genes (KEGG database and [22] without DTX1) with available Affymetrix Exon Array data. Differential expression analysis of NOTCH pathway and downstream genes was performed with empirical Bayes moderated t-statistics using limma R package 2.12.0 [71]. Contrasts were formulated to define the difference between different gene expression in groups of patient samples: tumor samples with higher $D T X 1$ expression, tumor samples with lower $D T X 1$ expression, and non-cancer samples. $P$-values for differential expression statistics were reported after FDR adjustment with Benjamini-Hotchberg correction [72] among 43 NOTCH pathway and 9 downstream genes, including DTX1 in both sets. Genes with FDR adjusted $p$-values below 0.05 were called significantly differentially expressed. Pathway-level statistics were computed by applying the limma function geneSetTest to the empirical Bayes moderated t-statistics for each contrast with the alternative hypothesis of "either" specifying that genes in the set are up or down regulated as a group.

\section{Expression-methylation correlation}

We utilized a correlation analysis to associate changes in gene expression with epigenetic regulation. Specifically, we computed Spearman correlation coefficients between gene-level estimates of DNA methylation and expression for each candidate gene inferred from outlier statistics. Candidate genes with negative correlations between expression and methylation were selected. All correlation analyses were performed using limma R package 2.12.0 [71].

\section{$P$-value calculation}

Log transform of gene expression values from array, normalized qRT-PCR gene expression values, DNA methylation $\beta$-values, and image field percentage values were compared for HNSCC and control samples using the Student $t$-test. We used $t$-test for all our validation step as it is more stringent than outlier test, used exclusively for discovery purposes. Bisulfite sequencing results were compared for HNSCC and control samples using the twotailed Fisher exact test.

\section{CONFLICTS OF INTEREST}

The authors declare no conflicts of interest.

\section{GRANT SUPPORT}

The work is supported by P30CA006973 (Cancer Center Core), NIDCR/NCI P50CA019032 Head and Neck Cancer SPORE (JAC and DAG), NIDCR/NIH Challenge Grant RC1DE020324 (JAC), NIDCR/NIH R21DE025398 (DAG), NIDCR/NIH R01DE023347 (JAC), K25CA141053 and R01CA177669 (EJF), NIH/NLM R01LM011000 (MFO), and NIDCR/NIH R01DE013152 (WMK).

\section{REFERENCES}

1. Siegel RL, Miller KD, Jemal A. Cancer statistics, 2016. CA Cancer J Clin. 2016; 66:7-30.

2. Torre LA, Bray F, Siegel RL, Ferlay J, Lortet-Tieulent J, Jemal A. Global cancer statistics, 2012. CA Cancer J Clin. 2015; 65:87-108.

3. Argiris A, Karamouzis MV, Raben D, Ferris RL. Head and neck cancer. Lancet. 2008; 371:1695-709.

4. Mignogna MD, Fedele S, Lo Russo L. The World Cancer Report and the burden of oral cancer. European journal of cancer prevention. 2004; 13:139-42.

5. Howlader N, Ries LA, Mariotto AB, Reichman ME, Ruhl J, Cronin KA. Improved estimates of cancer-specific survival rates from population-based data. J Natl Cancer Inst. 2010; 102:1584-98.

6. Tan M, Myers JN, Agrawal N. Oral cavity and oropharyngeal squamous cell carcinoma genomics. Otolaryngologic clinics of North America. 2013; 46:545-66.

7. Rocco JW, Leong CO, Kuperwasser N, DeYoung MP, Ellisen LW. p63 mediates survival in squamous cell carcinoma by suppression of p73-dependent apoptosis. Cancer Cell. 2006; 9:45-56.

8. Han J, Kioi M, Chu WS, Kasperbauer JL, Strome SE, Puri RK. Identification of potential therapeutic targets in human head \& neck squamous cell carcinoma. Head \& neck oncology. 2009; 1:27. 
9. Chung CH, Parker JS, Karaca G, Wu J, Funkhouser WK, Moore D, Butterfoss D, Xiang D, Zanation A, Yin X, Shockley WW, Weissler MC, Dressler LG, et al. Molecular classification of head and neck squamous cell carcinomas using patterns of gene expression. Cancer Cell. 2004; 5:489-500.

10. Carles A, Millon R, Cromer A, Ganguli G, Lemaire F, Young J, Wasylyk C, Muller D, Schultz I, Rabouel Y, Dembele D, Zhao C, Marchal P, et al. Head and neck squamous cell carcinoma transcriptome analysis by comprehensive validated differential display. Oncogene. 2006; 25:1821-31.

11. Leethanakul C, Knezevic V, Patel V, Amornphimoltham P, Gillespie J, Shillitoe EJ, Emko P, Park MH, EmmertBuck MR, Strausberg RL, Krizman DB, Gutkind JS, Head, et al. Gene discovery in oral squamous cell carcinoma through the Head and Neck Cancer Genome Anatomy Project: confirmation by microarray analysis. Oral Oncol. 2003; 39:248-58.

12. Agrawal N, Frederick MJ, Pickering CR, Bettegowda C, Chang K, Li RJ, Fakhry C, Xie TX, Zhang J, Wang J, Zhang N, El-Naggar AK, Jasser SA, et al. Exome sequencing of head and neck squamous cell carcinoma reveals inactivating mutations in NOTCH1. Science. 2011; 333:1154-7.

13. Stransky N, Egloff AM, Tward AD, Kostic AD, Cibulskis K, Sivachenko A, Kryukov GV, Lawrence MS, Sougnez C, McKenna A, Shefler E, Ramos AH, Stojanov P, et al. The mutational landscape of head and neck squamous cell carcinoma. Science. 2011; 333:1157-60.

14. Gaykalova DA, Mambo E, Choudhary A, Houghton J, Buddavarapu K, Sanford T, Darden W, Adai A, Hadd A, Latham G, Danilova LV, Bishop J, Li RJ, et al. Novel insight into mutational landscape of head and neck squamous cell carcinoma. PLoS One. 2014; 9:e93102.

15. Lui VW, Hedberg ML, Li H, Vangara BS, Pendleton K, Zeng Y, Lu Y, Zhang Q, Du Y, Gilbert BR, Freilino M, Sauerwein S, Peyser ND, et al. Frequent mutation of the PI3K pathway in head and neck cancer defines predictive biomarkers. Cancer discovery. 2013; 3:761-9.

16. Lui VW, Peyser ND, Ng PK, Hritz J, Zeng Y, Lu Y, Li H, Wang L, Gilbert BR, General IJ, Bahar I, Ju Z, Wang Z, et al. Frequent mutation of receptor protein tyrosine phosphatases provides a mechanism for STAT3 hyperactivation in head and neck cancer. Proc Natl Acad Sci USA. 2014; 111:1114-9.

17. Vanderkraats ND, Hiken JF, Decker KF, Edwards JR. Discovering high-resolution patterns of differential DNA methylation that correlate with gene expression changes. Nucleic Acids Res. 2013; 41:6816-27.

18. Irizarry RA, Ladd-Acosta $\mathrm{C}$, Wen $\mathrm{B}, \mathrm{Wu} \mathrm{Z}$, Montano $\mathrm{C}$, Onyango P, Cui H, Gabo K, Rongione M, Webster M, Ji H, Potash JB, Sabunciyan S, et al. The human colon cancer methylome shows similar hypo- and hypermethylation at conserved tissue-specific $\mathrm{CpG}$ island shores. Nature genetics. 2009; 41:178-86.
19. Artemov A, Aliper A, Korzinkin M, Lezhnina K, Jellen L, Zhukov N, Roumiantsev S, Gaifullin N, Zhavoronkov A, Borisov N, Buzdin A. A method for predicting target drug efficiency in cancer based on the analysis of signaling pathway activation. Oncotarget. 2015; 6:29347-56. doi: 10.18632/oncotarget.5119.

20. Ochs MF, Farrar JE, Considine M, Wei Y, Meshinchi S, Arceci RJ. Outlier Analysis and Top Scoring Pair for Integrated Data Analysis and Biomarker Discovery. IEEE/ACM transactions on computational biology and bioinformatics. 2013.

21. Li R, Ochs MF, Ahn SM, Hennessey P, Tan M, Soudry E, Gaykalova DA, Uemura M, Brait M, Shao C, Westra W, Bishop J, Fertig EJ, et al. Expression microarray analysis reveals alternative splicing of LAMA3 and DST genes in head and neck squamous cell carcinoma. PLoS One. 2014; 9:e91263.

22. Sun W, Gaykalova DA, Ochs MF, Mambo E, Arnaoutakis D, Liu Y, Loyo M, Agrawal N, Howard J, Li R, Ahn S, Fertig E, Sidransky D, et al. Activation of the NOTCH pathway in head and neck cancer. Cancer Res. 2014; 74:1091-104.

23. Fertig EJ, Markovic A, Danilova LV, Gaykalova DA, Cope L, Chung CH, Ochs MF, Califano JA. Preferential activation of the hedgehog pathway by epigenetic modulations in HPV negative HNSCC identified with metapathway analysis. PLoS One. 2013; 8:e78127.

24. Rathi KS, Gaykalova DA, Hennessey P, Califano JA, Ochs MF. Correcting transcription factor gene sets for copy number and promoter methylation variations. Drug development research. 2014; 75:343-7.

25. Afsari B, Geman D, Fertig EJ. Learning dysregulated pathways in cancers from differential variability analysis. Cancer Inform. 2014; 13:61-7.

26. van Wieringen WN, van de Wiel MA, van der Vaart AW. A Test for Partial Differential Expression. J Am Stat Assoc. 2008; 103:1039-1049.

27. Ghosh D. Genomic outlier detection in high-throughput data analysis. Methods Mol Biol. 2013; 972:141-53.

28. MacDonald JW, Ghosh D. COPA - cancer outlier profile analysis. Bioinformatics. 2006; 22:2950-1.

29. Gaykalova DA, Vatapalli R, Wei Y, Tsai HL, Wang H, Zhang C, Hennessey PT, Guo T, Tan M, Li R, Ahn J, Khan Z, Westra WH, et al. Outlier Analysis Defines Zinc Finger Gene Family DNA Methylation in Tumors and Saliva of Head and Neck Cancer Patients. PLoS One. 2015; 10:e0142148.

30. Han M, Liew CT, Zhang HW, Chao S, Zheng R, Yip KT, Song ZY, Li HM, Geng XP, Zhu LX, Lin JJ, Marshall KW, Liew CC. Novel blood-based, five-gene biomarker set for the detection of colorectal cancer. Clin Cancer Res. 2008; $14: 455-60$.

31. Hidalgo-Curtis C, Apperley JF, Stark A, Jeng M, Gotlib J, Chase A, Cross NC, Grand FH. Fusion of PDGFRB to 
two distinct loci at 3p21 and a third at 12q13 in imatinibresponsive myeloproliferative neoplasms. Br J Haematol. 2010; 148:268-73.

32. Yan J, Nie K, Mathew S, Tam Y, Cheng S, Knowles DM, Orazi A, Tam W. Inactivation of BANK1 in a novel IGH-associated translocation $\mathrm{t}(4 ; 14)(\mathrm{q} 24 ; \mathrm{q} 32)$ suggests a tumor suppressor role in B-cell lymphoma. Blood cancer journal, 2014. 4:e215.

33. Zhang P, Yang Y, Nolo R, Zweidler-McKay PA, Hughes DP. Regulation of NOTCH signaling by reciprocal inhibition of HES1 and Deltex 1 and its role in osteosarcoma invasiveness. Oncogene. 2010; 29:2916-26.

34. Ludwig L, Oswald F, Hoang-Vu C, Dralle H, Hildt E, Schmid RM, Karges W. Expression of the Grb2-related RET adapter protein Grap-2 in human medullary thyroid carcinoma. Cancer Lett. 2009; 275:194-7.

35. Lind GE, Danielsen SA, Ahlquist $T$, Merok MA, Andresen K, Skotheim RI, Hektoen M, Rognum TO, Meling GI, Hoff G, Bretthauer M, Thiis-Evensen E, Nesbakken A, et al. Identification of an epigenetic biomarker panel with high sensitivity and specificity for colorectal cancer and adenomas. Molecular cancer, 2011. 10:85.

36. Wang Y, Luo H, Li Y, Chen T, Wu S, Yang L. hsa-miR-96 up-regulates MAP4K1 and IRS1 and may function as a promising diagnostic marker in human bladder urothelial carcinomas. Molecular medicine reports. 2012; 5:260-5.

37. Wang SS, Purdue MP, Cerhan JR, Zheng T, Menashe I, Armstrong BK, Lan Q, Hartge P, Kricker A, Zhang Y, Morton LM, Vajdic CM, Holford TR, et al. Common gene variants in the tumor necrosis factor (TNF) and TNF receptor superfamilies and NF-kB transcription factors and non-Hodgkin lymphoma risk. PLoS One. 2009; 4:e5360.

38. Kaiser S, Park YK, Franklin JL, Halberg RB, Yu M, Jessen WJ, Freudenberg J, Chen X, Haigis K, Jegga AG, Kong S, Sakthivel B, Xu H, et al. Transcriptional recapitulation and subversion of embryonic colon development by mouse colon tumor models and human colon cancer. Genome Biol. 2007; 8:R131.

39. Cancer Genome Atlas, N. Comprehensive genomic characterization of head and neck squamous cell carcinomas. Nature. 2015; 517:576-82.

40. Homann N, Nees M, Conradt C, Dietz A, Weidauer H, Maier H, Bosch FX. Overexpression of p53 in tumor-distant epithelia of head and neck cancer patients is associated with an increased incidence of second primary carcinoma. Clin Cancer Res. 2001; 7:290-6.

41. Ha PK, Califano JA. The molecular biology of mucosal field cancerization of the head and neck. Critical reviews in oral biology and medicine. 2003; 14:363-9.

42. Matsuno K, Eastman D, Mitsiades T, Quinn AM, Carcanciu ML, Ordentlich P, Kadesch T, ArtavanisTsakonas S. Human deltex is a conserved regulator of Notch signalling. Nature genetics. 1998; 19:74-8.

43. Yamamoto N, Yamamoto S, Inagaki F, Kawaichi M, Fukamizu A, Kishi N, Matsuno K, Nakamura K, Weinmaster G, Okano H, Nakafuku M. Role of Deltex-1 as a transcriptional regulator downstream of the Notch receptor. J Biol Chem. 2001; 276:45031-40.

44. Fischer A, Klattig J, Kneitz B, Diez H, Maier M, Holtmann B, Englert C, Gessler M. Hey basic helix-loophelix transcription factors are repressors of GATA4 and GATA6 and restrict expression of the GATA target gene ANF in fetal hearts. Molecular and cellular biology. 2005; 25:8960-70.

45. Lee JC, Smith SB, Watada H, Lin J, Scheel D, Wang J, Mirmira RG, German MS. Regulation of the pancreatic proendocrine gene neurogenin3. Diabetes. 2001; 50:928-36.

46. Huber RM, Rajski M, Sivasankaran B, Moncayo G, Hemmings BA, Merlo A. Deltex-1 activates mitotic signaling and proliferation and increases the clonogenic and invasive potential of U373 and LN18 glioblastoma cells and correlates with patient survival. PLoS One. 2013; 8:e57793.

47. Lin YW, Deveney R, Barbara M, Iscove NN, Nimer SD, Slape C, Aplan PD. OLIG2 (BHLHB1), a bHLH transcription factor, contributes to leukemogenesis in concert with LMO1. Cancer Res. 2005; 65:7151-8.

48. Lindqvist CM, Lundmark A, Nordlund J, Freyhult E, Ekman D, Carlsson Almlof J, Raine A, Overnas E, Abrahamsson J, Frost BM, Grander D, Heyman M, Palle J, et al. Deep targeted sequencing in pediatric acute lymphoblastic leukemia unveils distinct mutational patterns between genetic subtypes and novel relapse-associated genes. Oncotarget. 2016; 7:64071-64088. doi: 10.18632/ oncotarget. 11773.

49. Xu Y, Wang Y, Liu H, Kang X, Li W, Wei Q. Genetic variants of genes in the Notch signaling pathway predict overall survival of non-small cell lung cancer patients in the PLCO study. Oncotarget. 2016; 7:61716-61727. doi: 10.18632/oncotarget.11436.

50. Korosec B, Glavac D, Volavsek M, Ravnik-Glavac M. ATP2A3 gene is involved in cancer susceptibility. Cancer Genet Cytogenet. 2009; 188:88-94.

51. Roos PH, Bolt HM. Cytochrome P450 interactions in human cancers: new aspects considering CYP1B1. Expert opinion on drug metabolism \& toxicology. 2005; 1:187-202.

52. McFadyen MC, Cruickshank ME, Miller ID, McLeod HL, Melvin WT, Haites NE, Parkin D, Murray GI. Cytochrome P450 CYP1B1 over-expression in primary and metastatic ovarian cancer. Br J Cancer. 2001; 85:242-6.

53. Pourreyron C, Reilly L, Proby C, Panteleyev A, Fleming C, McLean K, South AP, Foerster J. Wnt5a is strongly expressed at the leading edge in non-melanoma skin cancer, forming active gradients, while canonical Wnt signalling is repressed. PLoS One. 2012; 7:e31827.

54. Kaucka M, Plevova K, Pavlova S, Janovska P, Mishra A, Verner J, Prochazkova J, Krejci P, Kotaskova J, Ovesna P, Tichy B, Brychtova Y, Doubek M, et al. The planar cell polarity pathway drives pathogenesis of chronic lymphocytic leukemia by the regulation of B-lymphocyte migration. Cancer Res. 2013; 73:1491-501. 
55. Caldwell GM, Jones CE, Soon Y, Warrack R, Morton DG, Matthews GM. Reorganisation of Wnt-response pathways in colorectal tumorigenesis. Br J Cancer. 2008; 98:1437-42.

56. Jiang L, Zeng X, Yang H, Wang Z, Shen J, Bai J, Zhang Y, Gao F, Zhou M, Chen Q. Oral cancer overexpressed 1 (ORAOV1): a regulator for the cell growth and tumor angiogenesis in oral squamous cell carcinoma. Int J Cancer. 2008; 123:1779-86.

57. Mirghani H, Ugolin N, Ory C, Lefevre M, Baulande S, Hofman P, St Guily JL, Chevillard S, Lacave R. A predictive transcriptomic signature of oropharyngeal cancer according to HPV16 status exclusively. Oral Oncol. 2014.

58. Jackson PK, Eldridge AG, Freed E, Furstenthal L, Hsu JY, Kaiser BK, Reimann JD. The lore of the RINGs: substrate recognition and catalysis by ubiquitin ligases. Trends in cell biology. 2000; 10:429-39.

59. Yao K, Rizzo P, Rajan P, Albain K, Rychlik K, Shah S, Miele L. Notch-1 and notch-4 receptors as prognostic markers in breast cancer. International journal of surgical pathology. 2011; 19:607-13.

60. Ferretti E, Tosi E, Po A, Scipioni A, Morisi R, Espinola MS, Russo D, Durante C, Schlumberger M, Screpanti I, Filetti S, Gulino A. Notch signaling is involved in expression of thyrocyte differentiation markers and is down-regulated in thyroid tumors. J Clin Endocrinol Metab. 2008; 93:4080-7.

61. Izumchenko E, Sun K, Jones S, Brait M, Agrawal N, Koch W, McCord CL, Riley DR, Angiuoli SV, Velculescu VE, Jiang WW, Sidransky D. Notch1 mutations are drivers of oral tumorigenesis. Cancer Prev Res (Phila). 2015. 8:277-86.

62. Pickering CR, Zhou JH, Lee JJ, Drummond JA, Peng SA, Saade RE, Tsai KY, Curry JL, Tetzlaff MT, Lai SY, Yu J, Muzny DM, Doddapaneni H, et al. Mutational landscape of aggressive cutaneous squamous cell carcinoma. Clin Cancer Res. 2014; 20:6582-92.

63. Shao C, Bai W, Junn JC, Uemura M, Hennessey PT, Zaboli D, Sidransky D, Califano JA, Ha PK. Evaluation of MYB promoter methylation in salivary adenoid cystic carcinoma. Oral Oncol. 2011; 47:251-5.

64. Livak KJ, Schmittgen TD. Analysis of relative gene expression data using real-time quantitative PCR and the 2(-Delta Delta C(T)) Method. Methods. 2001; 25:402-8.

65. Li LC, Dahiya R. MethPrimer: designing primers for methylation PCRs. Bioinformatics. 2002; 18:1427-31.

66. Shao C, Tan M, Bishop JA, Liu J, Bai W, Gaykalova DA, Ogawa T, Vikani AR, Agrawal Y, Li RJ, Kim MS, Westra WH, Sidransky D, et al. Suprabasin is hypomethylated and associated with metastasis in salivary adenoid cystic carcinoma. PLoS One. 2012; 7:e48582.
67. Gentleman RC, Carey VJ, Bates DM, Bolstad B, Dettling M, Dudoit S, Ellis B, Gautier L, Ge Y, Gentry J, Hornik K, Hothorn T, Huber W, et al. Bioconductor: open software development for computational biology and bioinformatics. Genome Biol. 2004; 5:R80.

68. Carvalho BS, Irizarry RA. A framework for oligonucleotide microarray preprocessing. Bioinformatics. 2010; 26:2363-7.

69. Tibshirani, R. Hastie T. Outlier sums for differential gene expression analysis. Biostatistics. 2007; 8:2-8.

70. Ghosh, D. Discrete nonparametric algorithms for outlier detection with genomic data. J Biopharm Stat. 2010; 20:193-208.

71. Smyth GK. Limma: linear models for microarray data, in Bioinformatics and Computational Biology Solutions using R and BioConductor, R. Gentleman, R.V. Carey, S. Dudoit, R. Irizarry, and W. Huber, Editors. 2005, Springer: New York. 397-420.

72. Benjamini, Y. Hochberg Y. Controlling the False Discovery Rate: A Practical and Powerful Approach to Multiple Testing. J R Statist Soc B. 1995; 57:289-300.

73. Cancer Genome Atlas Research, N. Comprehensive genomic characterization of squamous cell lung cancers. Nature. 2012; 489:519-25.

74. Huang X, Takata K, Sato Y, Tanaka T, Ichimura K, Tamura M, Oka T, Yoshino T. Downregulation of the B-cell receptor signaling component $\mathrm{CD} 79 \mathrm{~b}$ in plasma cell myeloma: a possible post transcriptional regulation. Pathology international. 2011; 61:122-9.

75. Dornan D, Bennett F, Chen Y, Dennis M, Eaton D, Elkins K, French D, Go MA, Jack A, Junutula JR, Koeppen H, Lau J, McBride J, et al. Therapeutic potential of an anti-CD79b antibody-drug conjugate, anti-CD79b-vc-MMAE, for the treatment of non-Hodgkin lymphoma. Blood. 2009; 114:2721-9.

76. Arozarena I, Sanchez-Laorden B, Packer L, HidalgoCarcedo C, Hayward R, Viros A, Sahai E, Marais R. Oncogenic BRAF induces melanoma cell invasion by downregulating the cGMP-specific phosphodiesterase PDE5A. Cancer Cell. 2011; 19:45-57.

77. Fernandez-Zapico ME, Gonzalez-Paz NC, Weiss E, Savoy DN, Molina JR, Fonseca R, Smyrk TC, Chari ST, Urrutia R, Billadeau DD. Ectopic expression of VAV1 reveals an unexpected role in pancreatic cancer tumorigenesis. Cancer Cell. 2005; 7:39-49.

78. Hornstein I, Pikarsky E, Groysman M, Amir G, Peylan-Ramu $\mathrm{N}$, Katzav S. The haematopoietic specific signal transducer Vav1 is expressed in a subset of human neuroblastomas. J Pathol. 2003; 199:526-33. 